\title{
Bibliotecas, livros e jardins: os espaços e os objetos de saberes científicos nos relatos de viagem sobre as regiões do Rio de Janeiro, Minas Gerais e Bahia - 1815 e 1820
}

\section{Libraries, books and gardens: spaces and objects of scientific knowledge in travel reports on the regions of Rio de Janeiro, Minas Gerais and Bahia - 1815 and 1820}

Daniela Casoni Moscato*

\begin{abstract}
Resumo
$\mathrm{O}$ artigo analisa as concepções de Maximilian de Wied-Neuwied, Carl Friedrich Philipp von Martius e Johann Baptist Spix sobre os espaços e objetos de saberes no Rio de Janeiro, Minas Gerais e Bahia entre os anos de1815 e 1820. Por objetos e locais de saberes, entende-se que são veículos de circulação dos conhecimentos existentes no universo científico. Primeiramente, destacase o campo próprio da Ciência Moderna europeia e sua proliferação pelos espaços formais de conhecimento e pelas viagens filosóficas setecentistas e oitocentistas. Verifica-se como tais concepções sobre o mundo natural aparecem nos livros de viajantes, os quais tiveram contanto com a ciência portuguesa, na Metrópole e na Colônia. Num segundo momento, analisa-se esses elementos como recursos literários obrigatórios na literatura científica de viagem e símbolos de constatação do saberes sobre o mundo natural. Nesse sentido, tais temas são essenciais em uma cultura científica pautada em particulares experiências, mas dependente de ciclos de acumulação e redes de sociabilidades. Essas práticas são percebidas quando os estrangeiros elaboram testemunhos de determinadas regiões brasileiras.
\end{abstract}

Palavras- chaves: viajantes, história da ciência e América portuguesa

\section{Abstract}

The article analyzes the conceptions of Maximilian de Wied-Neuwied, Carl Friedrich Philipp von Martius and Johann Baptist Spix on the spaces and objects of knowledge in Rio de Janeiro, Minas Gerais and Salvador between 1815 and 1820. Such objects and places of knowledge are understood to be vehicles for circulating the existing knowledge in the scientific universe. First of all, the field of modern European science stands out with its proliferation through formal spaces of knowledge and Eighteenth-century philosophical

\footnotetext{
* Doutora em História pela UFPR. Professora da SEED-PR. Durante a pesquisa, a autora foi bolsista CAPES. E-mail: historiar7@gmail.com
} 
journeys. It verifies how such conceptions about the natural world appear in the books of travelers who had been in contact with the Portuguese science in the Metropolis and the Colony. In a second moment, these elements are analyzed as obligatory literary resources in the scientific literature of travel and symbols of verification of the knowledge about the natural world. In this sense, such themes are essential in a scientific culture based on particular experiences, but also dependent on cycles of accumulation and sociability networks. These practices are perceived when foreigners prepared "memories" about certain Brazilian regions.

Keywords: Travelers; History of Science; Portuguese America.

\section{A chegada de três viajantes naturalistas ao Brasil}

Em julho 1817, três viajantes naturalistas cruzaram o Atlântico em direções opostas. Maximilian de Wied-Neuwied (1782-1867) partiu da América à Europa. Ele era um aristocrata oriundo do principado de Neuwied e que aprofundou seus conhecimentos de ciências naturais na Universidade de Goëttingen. Na direção contrária, encontravam-se o médico Carl Friedrich Philipp von Martius (1794-1869) e o zoólogo Johann Baptist Spix (1781-1826). As três figuras em questão integraram uma geração de viajantes naturalistas que chegou ao Brasil nas primeiras décadas do século XIX. Aqui, conheceram e coletaram o maior número de espécies dos reinos naturais. Além deles, há o alemão Wilhelm Ludwig von Eschewege (1777-1855), o francês Augustin François César Prouvençal de Saint-Hilaire (1779-1856) e o russo Georg Heinrich von Langsdorff (1774-1852). Todos eram sujeitos que se dedicaram aos estudos das ciências naturais e figuras bem comuns nos estudos historiográficos sobre o período colonial. No entanto, para este artigo, nos deteremos nos três homens em trânsito naquele julho de 1817 e que estiveram no Brasil entre 1815 e 1820.

Wied-Neuwied chegou em 1815. A casa Wied financiou sua missão científica ao Brasil. Como era de praxe a muitos viajantes, Wied-Neuwied trazia consigo uma carta de apresentação de Joaquim Lobo da Silva, um português que conhecera na Universidade de Göttingen, para Antônio de Araújo de Azevedo (1754-1817), o Conde da Barca. No documento, o príncipe era descrito 
"como um protetor das ciências, homem de grandes conhecimentos botânicos, que tinha por objetivo unicamente realizar estudos da vegetação do Brasil".

Em suas andanças, percorreu a costa do Rio de Janeiro, o Espírito Santo, as regiões do Rio Paraíba, Jequitinhonha, os campos de Minas Gerais e o recôncavo baiano. Os naturalistas George Wilhelm Freyreiss (1789-1825) e Friedrich Sellow (1789-1831), que já estavam no Brasil desde 1812, colaboraram com a expedição, tanto com os seus conhecimentos de áreas da História Natural quanto com a compreensão razoável da língua portuguesa. ${ }^{2} \mathrm{O}$ material enviado à Alemanha durante esse período ajudou a construir o acervo do Museu de História Natural de Berlim. Além disso, Maximiliano compilou diversas informações, leituras e anotações dessa viagem. Esta produção literária foi inicialmente publicada na Alemanha em periódicos da época e em 1820 e 1821, publicou dois tomos sob o título de Viagem ao Brasil nos anos de 1815 e 1817.

Martius e de Spix conheceram-se em 1812, na cidade de Erlangen. Na ocasião, Spix já era um zoólogo reconhecido, experiente e trabalhava na Academia de Ciências de Munique. Martius era um promissor estudante de Medicina, o que lhe valeu uma indicação de Spix para atuar como pesquisador no Jardim Botânico da Academia de Ciências de Munique. Na viagem ao Brasil, Spix foi o encarregado de repassar as notícias para a Academia e para o rei, mas ambos, além de "estudar a fauna e a flora, [...] teriam que reunir dados geográficos, geológicos e climatológicos e, ainda, informações sobre os habitantes da região e as riquezas do solo, a estrutura política e econômica". ${ }^{3}$ O roteiro que foi percorrido pelos naturalistas bávaros incluiu Rio de Janeiro, São Paulo, Minas Gerais, Goiás, Bahia, Pernambucano, Piauí, Maranhão e Pará. A viagem acabou na cidade de Belém e de lá partiram para a Europa, em 1820. No total, foram $10.000 \mathrm{~km}$ percorridos e, durante esse tempo, separam-se por oito meses, para investigar os rios Amazonas, Solimões, Negro e Japurá.

Já na Alemanha, publicaram, em 1823, o primeiro tomo de livro Viagem pelo Brasil. O segundo tomo, em 1828 e, o terceiro, em 1831. Spix, entretanto, não viu os dois últimos. Ainda no Brasil, o zoólogo adoeceu e nunca mais se recuperou, vindo a falecer em 1826. Os três volumes são cuidadosos, bem

\footnotetext{
${ }^{1}$ SALLAS, Ana Luiza Fayet. A ciência do homem e o sentimento da natureza - viajantes alemães no Brasil do século XIX. Curitiba: Editora UFPR, 2013. p. 44-46

${ }^{2}$ Ibidem, p. 47.

${ }^{3}$ FITTKAU, Ernst Josef. Johann Baptist Ritter von Spix: primeiro zoólogo de Munique e pesquisador no Brasil. Rio de Janeiro: História, Ciências, Saúde - Manguinhos. Vol.III (suplemento), 2001 pp. 1112-1114. Ainda sobre Spix e Martius ver o trabalho: LISBOA, Karen Macknow. op. cit. v. 22, n 1, p. 179-194, jan/jun 2009, e LISBOA, Karen Macknow. Viagem pelo Brasil de Spix e Martius: quadros da natureza e esboços de uma civilização. Revista Brasileira de História. São Paulo, v.15, n 29, pp. 73-91, 1995.
} 
escritos e trazem detalhes dessa grande viagem. A descrição da natureza, dos costumes e gentios locais assemelha-se à narrativa de Wied, exaltando o "sentir romântico" diante do espetáculo, próprio do período. É o que se constata, em14 de julho de 1817, dia da chegada ao porto do Rio de Janeiro:

O dia estava encantadoramente claro e límpido, e vento favorável nos levou além do alto do cabo. Não tardou a patentear-se aos nossos olhos, embora ainda distante, a grandiosa entrada do porto do Rio de Janeiro. À direita e à esquerda elevam-se, como portões da baía, escarpados rochedos, banhados pelas vagas do mar (...). Depois do meio dia alcançamos, aproximando-nos cada vez mais do mágico panorama, os colossais portões de rocha, e finalmente por eles entramos no vasto anfiteatro, onde o espelho do mar reluzia como sossegado lago; onde espalhadas em labirintos, ilhas olorosas verdejavam, limitadas no fundo por uma serra coberta de matas, como jardim paradisíaco de exuberância e magnificência. ${ }^{4}$

Do mesmo modo, Wied-Neuwied dedica algumas linhas ao cenário de entrada do Rio de Janeiro "construída sobre várias colinas a beiramar" e que tem como fundo as "montanhas de forma cônica, arredondadas em cima e cobertas de florestas; embelezam infinitamente a paisagem, cujo primeiro plano é animado por grande quantidade de navios de todas as nacionalidades." ${ }^{5}$

O que eles viram no dia da chegada era um quadro conhecido da natureza exuberante, mesmo sendo um local novo para os três viajantes. Nos parágrafos dessa primeira visão do Rio de Janeiro, eles lançaram mão de recursos de escrita de uma narrativa clássica sobre a cidade colonial: a paisagem magnífica e exuberante que tinha em seu retrato os rochedos, o espelho do mar e a serra coberta de matas e jardins. É interessante lembrar que os narradores em questão eram leitores de outros viajantes e naturalistas que percorreram o globo, e a América portuguesa, com o olhar moldado para o mundo natural. Há, nesse tipo de livro de viagem, elementos próprios do universo científico, tais como: uso obrigatório dos termos científicos, as classificações das espécies, a menção a exemplares coletados e às remessas realizadas. Além desses tópicos, há os espaços e objetos de saberes, como jardins botânicos, museus, bibliotecas e livros apresentados nas memórias das viagens naturalistas. Esses elementos são distintos e, portanto, não serão tomados com igual valor. 0 espaço que o viajante visitou uma única vez não tem o mesmo significado que um livro que foi carregado e consultado durante toda a viagem.

\footnotetext{
${ }^{4}$ SPIX, Johann Baptist \& MARTIUS, Carl Friefrich Philipp. Viagem pelo Brasil: 1817-1820. Rio de Janeiro: Imprensa Nacional, 1983.Tomo I, p.43.

${ }^{5}$ WIED-NEUWIED, Maximilian. Viagem ao Brasil nos anos de 1815 e 1817. São Paulo: Editora Nacional, 1940. p. 30.
} 


\section{A Ciência Moderna e a circulação do conhecimento científico no século XVIII}

No século XVIII, a ideia da viagem fantástica e seu protagonista aventureiro e inventivo, muito comum no Renascimento, reformulou-se para a do viajante como testemunha autorizada, com formação, preparo, treino e conhecimentos linguísticos e científicos.

Já na segunda metade do século XVII, a viagem tinha interesses comerciais e científicos o que impulsionou áreas de conhecimento, como a das Ciências Naturais (a base da Ciência Moderna) que tinham como princípio a observação e a experimentação. Se, por um lado, mantinha-se o ar aventureiro e enigmático, elementos próprios do deslocar-se; por outro, a viagem tornou-se um empreendimento planejado cientificamente e que, entre outras coisas, verificou e analisou os antigos trajetos, contestou os mitos e os lugares fantásticos. Essa nova característica e as preciosas informações que ela fornecia sobre todos os cantos do mundo amparavam os acirrados debates científicos e a função utilitarista dos Impérios da Modernidade. 0 homem em trânsito passava a ser uma testemunha qualificada do lugar visitado.

Acreditava-se que o viajante-cientista ou naturalista era capaz de observar e relatar de forma "fidedigna" o que havia visto na jornada. A lenta e progressiva mudança na forma de viajar e a maneira de se ver a persona do viajante eram parte do chamado "Movimento Ilustrado", o qual desenvolveu-se, de maneira particular, em muitos territórios europeus e suas respectivas colônias. ${ }^{6} \mathrm{Na}$ altura, algumas as áreas específicas estavam delineadas e a viagem tornou-se, ainda mais, uma fonte de informação.

Cumpre aqui observar que esse processo foi lento e progressivo. Angela Domingues menciona que as antigas descrições dos locais distantes e visitados foram "alteradas e corrigidas à medida que a ciência europeia e sua metodologia se renovavam e evoluíam, que os modos de observação e as perspectivas valorizadas nas formas de encarar outras realidades se alteravam e os instrumentos de observação científica se tornavam mais exatos e precisos." Essa nova característica científica, com preciosas informações sobre todos os cantos do mundo, também amparava debates e a função utilitarista dos Impérios da Modernidade, que viam nos novos ares científicos mais possibilidades aos reinos. À medida que a manutenção da esfera política

\footnotetext{
${ }^{6}$ Sobre esse tema, ver: VOVELLE, Michel. O homem do Iluminismo. Lisboa: Editorial Presença, 1997. ARAÚJO, Ana Cristina. A cultura das Luzes em Portugal: temas e problemas. Lisboa: Livros Horizonte, 2003.

${ }^{7}$ DOMINGUES, Ângela. O Brasil nos relatos de viajantes ingleses do século XVIII: produção de discursos sobre o Novo Mundo. Revista Brasileira de História. São Paulo, v. 28, nº 55, p. 133-152. 2008, p. 134.
} 
vinculava-se ao controle do conhecimento, podia, entre outras coisas, favorecer esses Estados economicamente e "civilizacionalmente, através da conquista de vantagens comerciais sobre novos espaços geográficos, novos produtos e novas rotas." ${ }^{8}$ Assim, as informações adquiridas em outros locais do globo seriam revertidas em benefícios comerciais e políticos. Do mesmo modo, contribuíam para a valorização do indivíduo portador desse saber, bem como da nação à qual pertencesse.

Se estava posta uma outra forma de viajar, era essencial que se modificasse a maneira de contar sobre o Novo Mundo. Das novas sensibilidades que a Ciência Moderna apresentou à pessoa viajante, algumas características se sobressaem nas memórias do final do setecentos e do oitocentos: as referências bibliográficas (citação de autores e obras) e a menção a elementos de ordem científica ${ }^{9}$ (Gabinetes de História Natural, Jardins Botânicos, livros, bibliotecas e procedimentos de coleta e preparo de coleções). Neste artigo, nos deteremos nesta última. Queremos pensar como tais espaços e elementos do saber científico foram narrados por viajantes que estiveram no Brasil nas duas primeiras décadas do século XIX.

Há que se perguntar, entretanto, como e porque tais recursos literários ocuparam as páginas de relatos de viagem do final do século XVII e nos séculos XVIII e XIX. Para entender esse aspecto, deve-se perceber que os novos conhecimentos sobre a Ciência Moderna e sobre a viagem edificaram uma cultura científica especializada, que transitou pelos locais de sociabilidade científica, pelas redes epistolares e pelas leituras de livros de viagem. Esses ambientes e suas práticas são importantes à compreensão das viagens filosóficas, naturalistas ou científicas dos séculos XVIII e XIX. ${ }^{10}$

Pode-se entender esse cenário de trânsito dos conhecimentos pela "República das Letras". Uma de suas características foi a circulação do conhecimento e da informação pelos espaços de sociabilidade ilustrada na Europa. É necessário retomar o fato de que os cafés, os salões, as bibliotecas particulares, os gabinetes de leitura, entre outros, foram vias para diferentes informações, propagando, igualmente, a imagem do ilustrado em Paris, Madri ou Lisboa, com um papel importante na edificação da Ciência Moderna e na

\footnotetext{
${ }^{8}$ Ibidem, p. 141.

${ }^{9}$ Há que se esclarecer algumas expressões que serão usadas neste artigo: “ordem científica”, “campo científico" e "comunidade científica". Tais termos não eram usais no vocabulário do período estudado. Entretanto, são apropriados para a análise aqui proposta.

${ }^{10}$ BADINTER, Elisabeth. As paixões intelectuais, v.1: Desejo de glória (1735-1751). Trad. Clóvis Marques. Rio de Janeiro: Civilização Brasileira, 2007.
} 
manutenção dos impérios que a sustentavam. ${ }^{11}$ Essa menção faz-se necessária para percebermos os ambientes e as estratégias comuns a esses homens que formavam uma elite e "almejavam alcançar as posições de comando da cultura e iluminar de cima para baixo". ${ }^{12}$

Sobre tais recintos, já no final do século XVII e ao longo do século XVIII, foram criados alguns ambientes dedicados ao estudo da natureza, como os gabinetes, os jardins botânicos, os museus, as academias e as universidades. A Universidade de Göttingen (onde estudou Maximilian Wied-Neuwied) e a seiscentista Academia das Ciências de Paris são apenas dois exemplos muito frequentados por naturalistas de todo o globo. Nesses locais, tinha-se a oportunidade de visitar a biblioteca, ouvir a sessão de leitura de uma memória científica, adquirir publicações, trocar correspondências, assistir a uma aula específica sobre filosofia natural e integrar os grupos interessados nos materiais de viagens. Os muitos relatos de viagem do período testemunham o rápido desenvolvimento desses ambientes no decurso do século XVIII, que tinham a universalidade como característica e "prefiguravam nitidamente aquilo a que chamamos hoje uma moderna comunidade científica internacional". ${ }^{13}$

Para que tal intercâmbio fosse alimentado, foi necessária a adoção de um padrão de valores, linguagens e práticas. Nessa dinâmica, mantinham-se determinadas singularidades, como um conteúdo disciplinar de uma universidade, e estabelecia-se um mesmo horizonte de referência para as instituições científicas ou, nas palavras de Ferrone, sentia-se "a existência de um quadro unitário de valores, de linguagem, de práticas. ${ }^{14}$

O horizonte de referência do qual fala Ferrone explica como a cultura científica europeia e seus padrões atravessaram fronteiras e se multiplicaram. Tal processo pode ser percebido na grande rede de sociabilidade científica que articulou instituições, indivíduos e teorias científicas. 0 essencial de uma rede deste tipo é o fato de que "os recursos estão concentrados em poucos locais - nas laçadas e nos nós - interligados - fios e malhas. Essas conexões transformam os recursos esparsos numa teia que parece se estender por toda a parte". ${ }^{15}$ A noção de rede pode esclarecer o porquê da valorização e da pro-

\footnotetext{
${ }^{11}$ Sobre os salões franceses, ver HELLEGOUARC'H, J. L'esprit de societé: cercles et salons parisiens au XVIII siécle. Paris: Garnier, 2000.

${ }^{12}$ DARNTON, Robert. Os dentes falsos de George Washington: um guia não convencional para o século XVIII. Trad. José Geraldo Couto. São Paulo: Companhia das Letras, 2005, p.19. Sobre a República das Letras, ler também: CHARTIER, Roger. 0 homem de letras. In: .VOVELLE, Michel. op. cit., pp.119-153

${ }^{13}$ FERRONE, Vincenzo. 0 homem de ciência. In: VOVELLE, op. cit., p.165

${ }^{14}$ Ibidem.

${ }^{15}$ LATOUR, Bruno. Ciência em ação: como seguir cientistas e engenheiros sociedade afora. São Paulo: Editora da
} 
pagação, em determinados espaços, de padrões científicos e indivíduos, pois as laçadas ou os nós podem ser qualquer um desses três elementos.

Nesse sentido, entende-se que os gabinetes de história natural, jardins botânicos, museus de história natural e bibliotecas são alguns desses nós de uma grande rede científica. Esses locais foram destinos certos dos homens de ciência e propiciaram encontros e debates. Para que tal conjuntura seja esclarecida para o leitor, tentemos imaginar um gabinete. Ele era um aglomerado de objetos, que iam de coleções de moedas a fetos de animais exóticos. Esse interesse por espécies naturais de lugares longínquos não era novidade, pois o colecionismo era praxe entre nobres e enriquecidos. ${ }^{16}$ Desde o século XV, os chamados "gabinetes de curiosidades" reuniam globos terrestres, relógios, moedas, estátuas da Antiguidade, plantas exóticas, animais, minerais, entre outros.

Fernanda de Camargo-Moro elenca a origem de alguns desses espaços na Europa e esclarece como se tornaram uma espécie de amostragens do mundo: em 1568, foi criado em Bolonha o Teatro della Natura, pelo naturalista e professor paduano Ulisse Aldrovandi (1522-1605). Vinte e cinco anos depois, o rei Henri IV, da França, criou em Montpellier o Jardin des Plantes, que abrigava diversas coleções de História Natural e era visitado por curiosos e letrados; seu filho, Luís XIII, criou o Jardim Real das Plantas Medicinais em 1635, que mais tarde deu origem ao famoso Jardin du Roi. Entre 1739 e 1788, o Jardin foi dirigido por uns dos principais naturalistas do Iluminismo: Georges-Louis Leclerc, o conde de Buffon. Em 1793, esse espaço foi transformado no Museu Nacional de História Natural. ${ }^{17}$

Conforme a curiosidade era substituída pela ciência, entendida como um conhecimento especializado, utilitário e pragmático, esses acervos reais e particulares já estudados, catalogados e organizados passaram a compor, no final do século XVII e durante o século XVIII, parte das coleções de muitos

\footnotetext{
Unesp, 2000. pp. 294-329.

${ }^{16}$ Para mais detalhes sobre as coleções reais, indicamos a obra de PEREIRA, Magnus Roberto de Mello "Las cosas singulares de piedras, animales, plantas": la formación y el funcionamiento de la red imperial española de remesas centíficas en el Virreinato del Río de la Plata. Anais do Museu Paulista. São Paulo. N. Sér. v. 21. n.1. p. 91-138. jan.-jun. 2013. p. 93; o artigo de CAMARGO-MORO, Fernanda. "Câmara de maravilhas, studioli e gabinetes de curiosidades: Vandelli e sua circunstância." In: CAMARGO-MORO, Fernanda \& KURY, Lorelai O Gabinete de curiosidades de Domenico Vandelli. Dantes Editora, s./l. 2008; e CERÍACO, Luis Miguel Pires; BRIGOLA, José Carlos Pires; OLIVEIRA, Paulo de. "Os monstros de Vandelli e o percurso das coleções de história natural do século XVIII." In: FIOLHAIS, Carlos; SIMÕES, Carlota \& MARTINS, Décio (eds.). História da Ciência Luso-Brasileira; Coimbra entre Portugal e o Brasil. Coimbra: Imprensa da Universidade de Coimbra, 2013.
}

${ }^{17}$ CAMARGO-MORO, op. cit. 
museus europeus de história natural ${ }^{18}$, como o British Museum (1753), o Museu da Ajuda (1768), o Museu de História Natural de Coimbra (1772) e o Muséum d'Histoire Naturelle (1793). De acordo com Magnus Pereira, esses espaços significavam mais do que a simples reunião de curiosidade; os chamados Teatros da Natureza, por exemplo, "además de divulgarem la ciencia como forma superior de conocimento, fueron utilizados como instrumentos de afirmación del poder de las casas reinantes". ${ }^{19}$

A representação científica no período moderno era símbolo de poder dos reinos. Nas amostras de peixes, aves, conchas, borboletas, minérios, crânios, ovos de tartarugas, coleções de plumas e serpentes, distribuídas em mesas, frascos de vidro, papéis cuidadosamente preparados e vitrines havia a dupla denotação de poder. Primeiro, o do erário que permitia o financiamento de viajantes e a compra de coleções que enriquecessem aqueles ambientes. 0 segundo, o poder ilustrado, que revelava as preocupações modernas e utilitárias para o seu progresso e o desenvolvimento dos reinos, consequentemente, dos seus súditos. O Reino de Espanha é um belo exemplo de transição das coleções de curiosidades para os ambientes institucionais e, mais tarde, científicos. Tradicionalmente, a família real espanhola constituía coleções de espécies, amostras, animais das colônias americanas e de locais como China, Japão e Índia, além de adquirir coleções particulares, como a de Pedro Franco Dávila. Nas últimas duas décadas do século XVIII, uma política de modernização urbana e científica reuniu essas inusitadas coleções em um único complexo, o "Salão do Prado", que incluía gabinete de história natural, jardim botânico e um observatório astronômico. Foi inaugurado em 1781 e era a materialização do mecenato real voltado à cultura científica. ${ }^{20}$

Feita a apresentação de uma significativa parte do universo científico nos séculos XVII e XVIII, é preciso questionar o seguinte: por que espaços de ciência estão nas narrativas dos viajantes? Há de se lembrar que todo relato ou memória de viagem é um produto literário e que traz elementos próprios do tempo de sua produção. Miriam Lifchitz Moreira Leite ainda esclarece que o livro de viagem deve ser pensado como uma fonte intermediária "entre o documento pessoal (diário íntimo e correspondência) e o relatório final (memória descritiva com

\footnotetext{
${ }^{18}$ Sobre os detalhes da transição do colecionismo de curiosidades para o de caráter científico ver PEREIRA, Las cosas singulares ..., p. 95.

${ }^{19}$ Ibidem, p. 92.

${ }^{20}$ PEREIRA, Magnus Roberto de Mello \& CRUZ, Ana Lúcia Rocha Barbalho. O viajante instruído: os manuais portugueses do Iluminismo sobre métodos de recolher, preparar, remeter, e conservar productos naturais. In: DORÉ, Andréa \& SANTOS, Antonio César de Almeida. Temas Setecentistas. Curitiba: UFPR/SCHLA, 2009, p. 102.
} 
objetivos políticos, econômicos e educacionais)." ${ }^{21}$ Uma das maneiras de estudar essa escrita de viagem é conhecer para quem escreviam.

\section{O que os viajantes escreveram sobre os espaços científicos em Portugal nos séculos XVIII e XIX?}

Diante dessa natureza brasílica classificada e domesticada, o sujeito em trânsito testemunhou, entre outras coisas, um novo tema oriundo do capital científico em construção. Sobre as representações nos relatos de viagens ao Brasil, tem-se os espaços e objetos científicos de instrução e de propagação da História Natural. Nos livros analisados para este artigo, há passagens sobre museus, Jardins Botânicos, bibliotecas e universidades em Portugal, como foi o caso de Wied-Neuwied, que finalizou sua expedição brasileira em Lisboa.

Wied- Neuwied chegou à foz do Tejo no dia 01 de julho de 1817. De acordo com a Memória, após a dissipação de um nevoeiro, os navegantes avistaram "as duas margens do rio, que se erguiam suavemente inclinadas; cobriam-nas aldeias, casas de campo, igrejas. Apesar da largura do rio, distinguiam-se a brancura das casas e os campos que já haviam sido ceifados." Ao meio-dia, o navio ancorou e, dele, Wied-Neuwied pode ver a bela Torre de Belém e, mais ao alto, o Palácio da Ajuda. Afora isso, via também a ocupação urbana que se espalhava pelas duas margens, com suas casas, seus grandes edifícios e as igrejas. ${ }^{22}$

Nos parágrafos que seguem, o naturalista entretém o leitor com o interior da cidade, que nada lembra a descrição anterior. A Lisboa vista do grande Tejo desaparece e o que ocupa as páginas são as casas separadas e mal conservadas, as ruas desiguais e sujas, o desagradável mau cheiro e a falta de vigilância e iluminação noturna. Portugal é "sob vários pontos de vista, muito mais atrasado que os outros países da Europa. A própria capital não possui várias instituições úteis que se encontram em quase todas as pequenas cidades dos países civilizados da Europa." ${ }^{23}$

A descrição de Lisboa, ou da "atrasada" capital europeia, foi alimentada pela visita ao chamado Complexo da Ajuda (local de preparo para as expedições luso-brasileiras pelas colônias ${ }^{24}$ - com seu jardim botânico e o Real Museu:

\footnotetext{
${ }^{21}$ LEITE, Miriam Lifchitz Moreira. Livros de Viagem (1803-1900). Rio de Janeiro: Editora UFRJ,1997.

${ }^{22}$ WIED, op. cit. p. 460.

${ }^{23}$ Ibidem, p. 461.

${ }^{24}$ PEREIRA. M. R. de M. \&CRUZ. Instructio Peregrinatoris. Algumas questões referentes aos manuais portugueses sobre métodos de observação filosófica e preparação de produtos naturais da segunda metade do século XVIII. In: KURY, Lorelai \& GESTEIRA, Heloisa (orgs.). Ensaios de História das Ciências no Brasil: das
} 
Os estrangeiros vêm com muito maior interesse o 'gabinete de história natural' que não fica longe do palácio, e é contíguo ao jardim botânico. Dizem que aquele já foi muito mais rico; todavia contem ainda muitas coisas curiosas, provenientes das possessões portuguesas nas diferentes partes do mundo. Napoleão, que considerava justa presa todos os objetos em que podia pôr a mão, conquistou uma fama imperecível entre os portugueses pela pilhagem desse gabinete: pois ele foi o primeiro conquistador que não poupou siquér os estabelecimentos científicos, nos diferentes povos que despojou. Havia outrora nessas salas uma importante coleção de animais do Brasil. Atualmente, ela não mais existe: achase em Paris (...) Possui, contudo, ainda várias peças de grande valor, ente outras uma coleção de armas, utensílios e ornamentos de penas das diferentes tribus do Brasil, principalmente do Maranhão; as cores desses ornamentos são magníficas, porquanto são feitas de penas de araras, ararunas, tucanos, guarubas e outras belas aves. Há também entre as raridades desse museu dois 'manatís' com 6 a 8 pés de comprimento. 0 jardim botânico nem vale a pena ser citado: compõese de quadras cercadas de sebes baixas e cortadas a tesoura, e onde vegetam, em estado meio selvagem, plantas comuns. Duas pequenas estufas estão quase vazias; vêm-se ao lado dela grupos de cactos muito vigorosos, e um dragoeiro (Dracaena Draco), cujos frutos estavam maduros. O estudo da natureza não parece contar muitos amadores em Portugal, e os próprios produtos naturais do país são em grande parte estudados por naturalistas estrangeiros, e por isso não nos deve surpreender que, aqui se descuida da pesquisa dos exemplares da história natural das colônias dêste reino..$^{25}$

Não há originalidade nesse relato de Wied-Neuwied. Viu-se anteriormente que os espaços de ciência pelo mundo (museus, gabinetes, jardins botânicos, universidades) tornaram-se parte dos roteiros desses viajantes. Segundo Brigola, "à medida que se acumulavam descrições, opiniões, ou simples referências ao colecionismo e às atividades museais", as impressões estrangeiras deixadas alimentaram um "importante capítulo do Livro dos Museus em Portugal”. Quando os salões particulares e suas coleções de moedas foram substituídos pelos Museus de História Natural e Jardins Botânicos, esses se tornaram "os espaços museológicos preferidos pelos viajantes; a sua descrição e avaliação obrigá-los-á a apurar a sensibilidade crítica, a revelar conhecimentos científicos, a comparar realidades nacionais". ${ }^{26}$

É importante atentar para os traços que Wied Neuwied fez sobre algumas instituições científicas portuguesas. Na descrição do Complexo da Ajuda, o estrangeiro expôs as informações significativas sobre a história daquele espaço, como a dos muitos exemplares de espécies apropriados na ocupação napoleônica em 1807. Entretanto, o que mais nos interessa é que, para ele,

Luzes à nação independente. Rio de Janeiro: EdUERJ, 2012.

${ }^{25}$ WIED-NEUWIED, op. cit. p.464.

${ }^{26}$ BRIGOLA, João Carlos. Os viajantes e o livro do museu. Porto: Edição Dafne/CHAIA, 2010. p. 10. 
Portugal descuidava da história natural. Sabe-se que esse tipo de interpretação não era isolado e que a crença na inexistência de uma ciência portuguesa pontuou outros relatos de viagem e incrementou o estereótipo do "atraso português”. Por essa razão, é preciso não tomar ao pé da letra esses relatos "e suspender a crença de que eles contêm descrições etnográficas sobre o atraso português. Melhor será considerá-los como um indicador da capacidade, sobretudo de Lisboa, para atrair viajantes e promover a formação de uma cultura cosmopolita". ${ }^{27}$ Nesse sentido, há que se perguntar: Wied-Neuwied apenas repetia o que se ouvia, o que se lia e o que se propagava nos círculos científicos europeus sobre as ciências portuguesas?

Um outro estudante de Göttingen esteve em Portugal entre 1797 e 1799. O médico e naturalista Heinrich-Friedrich Link visitou o Complexo da Ajuda e os apontamentos assemelham-se aos de Wied Neuwied, seu colega de universidade:

O Real Gabinete de História Natural na Ajuda merece, no entanto, ser visto. Talvez não possa ser comparado com o parisiense ou mesmo com o Gabinete de Madri, é pequeno, não há uma única secção bem guarnecida, vêem-se menos coisas brasileiras do que seria de se esperar, mas encontram-se algumas peças dignas de nota. [...] Um laboratório químico insignificante encontra-se no mesmo edifício e imediatamente a seguir o jardim botânico." ${ }^{28}$

Pode-se dizer que os dois alemães, pela formação em filosofia natural, tiveram avaliações mais exigentes sobre o lugar que conheciam. Ambos tinham ferramentas e capital científico para comparar o jardim português e apontar, na visão de um naturalista ou cientista, a ausência de algum objeto, os erros técnicos no armazenamento de determinadas amostras e a falta de coleções substâncias sobre as colônias portuguesas. Por outro lado, há viajantes não especialistas que incluíram nas narrativas os espaços científicos. Cabe aqui retomar, rapidamente, que nos séculos XVIII e XIX a investigação, a classificação e a domesticação dos três reinos naturais (animal, vegetal e mineral) não eram exclusividade dos formados em Filosofia Natural ou Medicina. Outros homens e mulheres se dedicaram a coletar plantas, estudar os herbários e as novas nomenclaturas, frequentar jardins botânicos e gabinetes. Sobre isso,

\footnotetext{
${ }^{27}$ CURTO, Diogo Ramada. D. Rodrigo de Sousa Coutinho e a Casa Literária do Arco do Cego. In: CAMPOS, Fernanda Maria Guedes; CURTO, Diogo Ramada; TUDELA, Ana Paula. A Casa Literária do Arco do Cego: bicentenário, (1799-1801): “ sem livros não há instrução". Lisboa: Imprensa Nacional/Casa da Moeda, 1999. p. 26. ${ }^{28}$ LINK, Heinrich-Friedrich. In: BRIGOLA, João Carlos. Os viajantes e o livro do museu. Porto: Edição Dafne/ CHAIA, 2010. p. 20.
} 
Keith Thomas aponta como a revolução científica proporcionou às mulheres e aos homens novas sensibilidades. ${ }^{29}$

Janet Schaw esteve no espaço entre 1774 e 1776; em sua narrativa, destacou as espécies mantidas no palácio de inverno do rei e no Jardim Botânico. Schaw caminhou pelos passeios cobertos de cascalho e ornamentados por cercas vivas e fileiras de jasmim, se assustou "com a saudação de um elefante", se encantou com o grande aviário oval que abrigava aves multicoloridas, rodeadas por laranjeiras, murtas e uma "variedade de outras plantas perenes, e ao meio há um bebedouro que recebe um suprimento constante de água das mãos de uma estátua colocada na parte alta, correndo até abaixo, de modo a estar sempre fresca". Esclareceu que tal coleção era "um tributo anual à rainha dos Brasis, da Madeira, e de fato de todos os domínios onde existem." Se o relato de Shaw fosse o de um naturalista, teríamos mais detalhes sobre o laboratório, a biblioteca e a Casa de Risco, mas mesmo assim, a viajante apresenta um testemunho sobre a riqueza dos reinos da natureza disponível a estudiosos e curiosos:

Um pouco mais adiante, encontramos galinhas indianas de todas as denominações [...]. Foi-me impossível nomeá-las todas, mas elas estavam bem representadas nos relatos indianos que temos em casa. [...]

Entramos agora em um campo, ao fim de uma rua de pequenas casas, que descobrimos serem habitadas por animais de natureza a mais nociva, como doninhas, etc. Um em particular era habitado por roedores do Brasil, de um grande tamanho. Todos vieram espiar pelas grades, como muitas freiras, se estivem confinadas por acharem que causariam dano à sociedade se estivessem livres. Atrás de nós encontramos um grande zoológico, em forma de quadra. Aqui estão leões, leopardos, panteras, ursos e lobos. Ambas leoas e panteras tem filhotes. As últimas são os gatinhos mais bonitos que se podem conceber. Esqueci do tigre, que também tem uma jovem família. Ainda que haja um número de oficiais para atender esta quadra feroz, eles não são limpos e o cheiro é intolerável. ${ }^{30}$

É claro que as narrativas de Wied-Neuwied, Link e Schaw são distintas. Há, entre elas, quase meio século decorrido (1774 e 1817), e diversos acontecimentos modificaram o aspecto do local. O maior deles ocorreu em 1808, quando o naturalista francês Geoffroy Saint-Hilaire coletou, a mando de Napoleão, milhares de objetos da Ajuda. Além do mais, o interesse dessas

${ }^{29}$ THOMAS, Keith. O homem e o mundo natural: mudanças de atitude em relação às plantas e aos animais, 1500-1800. São Paulo: Companhia das Letras, 1988.

${ }^{30} \mathrm{SCHAW}$, Janet. Journal of a Lady of Quality: Being the Narrative of a Journey from Scotland to the West Indies, North Carolina, and Portugal, in the Years 1774-1776. Un. of Nebraska Press, 2005. Apud: BRIGOLA, Os viajantes... pp.49-50. 
descrições é identificar um novo tema nos relatos de viagem dos séculos XVIII e XIX, perceber como tais espaços eram narrados e avaliar esses extratos como parte do capital científico de determinadas redes de sociabilidade.

\section{Jardins e bibliotecas: a história natural nos relatos sobre o Rio de Janeiro, Minas Gerais e Bahia}

Os viajantes analisados neste artigo têm aspectos em comum que esclarecem o lugar que ocupavam no leque das expedições que estiveram no Brasil nas duas primeiras décadas do século XIX. Todos eles tiveram educação formal em História Natural e viajaram pelos trópicos com objetivos científicos. Em outras palavras, deveriam recolher informações detalhadas e, se possível, inéditas dos reinos naturais. Quando atracavam no porto do Rio de Janeiro, geralmente tinham em mãos uma carta de apresentação e, alguns, a autorização do próprio governo português. Esses requisitos abriam as portas de residências da elite portuguesa e brasileira, como também a casa de estrangeiros que poderiam auxiliar nos objetivos da viagem.

O retrato desses sujeitos errantes é parte essencial na construção de suas narrativas sobre o Brasil. Em relação aos objetos e espaços de instrução e científicos, viu-se que eram temas comuns nos livros de viajantes, e não exclusividade do naturalista. Entretanto, também se pontuou que o olhar treinado pela ciência e os instrumentos próprios deste campo dão ferramentas distintas à escrita. Em se pensando por esse lado, as descrições dos viajantes-cientistas sobre esses ambientes são mais detalhadas? Esses sujeitos apresentam sentidos que somente alguém do campo científico poderia entender? É possível identificar um padrão de narrativa ou mesmo de relação interpessoal com esses espaços? São essas questões que continuam a nortear este artigo e não a tentativa de usar as descrições desses livros de viagens na comprovação de determinados espaços de instrução e científicos nessas três regiões.

No que diz respeito às ciências, tentou-se criar nos trópicos um complexo semelhante ao de Lisboa. D. Rodrigo de Souza Coutinho (Ministro da Marinha e Negócios Ultramarinos entre 1796 e 1812) instituiu a Academia da Marinha com todos os instrumentos, livros, cartas, modelos, planos, máquinas que possuía em Portugal. Em 1808, o Museu Nacional foi fundado com as peças do gabinete de curiosidades de D. João, que mantinha animais empalhados, artefatos indígenas, peças mineralógicas, espécies naturais, gravuras e peças de arte. Em 1810, foi iniciada no Real Horto a aclimatação de especiarias e árvores frutíferas como cravo-da-índia, pimenta-do-reino, canela, árvores de cânfora, noz-moscada, mangueiras, frutas do conde, jambeiros e outras 
mais. Nesse mesmo ano, criou-se a Academia Militar, que divulgou o ensino da história natural, da química, da matemática e da física. Em 1813, foi a vez da Escola Cirúrgica, sediada no Hospital da Misericórdia; e, finalmente, em 1814, a Real Biblioteca abriu suas portas ao público. ${ }^{31}$

Nas memórias analisadas, não se percebem possíveis dificuldades dos viajantes para frequentar esse cenário científico em construção e sujeitos ligados às luzes portuguesas. Em 1808 John Mawe durante a sua estada brasileira trabalhou para D. Rodrigo de Souza Coutinho. Outros foram convidados a conhecer tanto os espaços reais quanto as bibliotecas particulares, como foi o caso de Saint-Hilaire, Wied, Spix e Martius. Sobretudo, tem-se de ter sempre a vista que esses eram viajantes qualificados. Homens de ciência que chegaram aos trópicos com livros, instrumentos, cartas de recomendação e recursos para custear a viagem. Eram bem recebidos nos círculos da elite e pelos locais menos abastados. Esses últimos poderiam ser beneficiados pelos seus conhecimentos (como um atendimento médico) ou financiamento (contratado para auxiliar na expedição por terra e rios).

Ainda no Rio de Janeiro, Wied narrou o preparo de sua expedição e que nos dá ideia do empreendimento que era a viagem filosófica. $O$ extrato também permite perceber como um nobre cientista era acolhido:

(...) passaporte e cartas de recomendação dirigidas aos capitães-gerais das províncias, concebidas em termos tão lisongeiros para mim, que duvido se tenham dado iguais aos viajantes que me precederam As autoridades eram solicitadas a nos prestar auxílio e proteção toda vez que o necessitássemos e a fazer chegar nossas coleções ao Rio, fornecendo-nos, quando pedíssemos, soldados, guias, carregadores e animais de carga. Dois jovens alemães, Srs. Sellow e Freyreiss, que conheciam muito bem os costumes e a língua da região, prometeram acompanhar-me na minha viagem ao longo da costa oriental, até Caravelas, auxiliando-me nas pesquisas. Levávamos dezesseis muares, carregando cada um duas caixas de madeira cobertas de couro cru, que as abrigava da chuva e da umidade. Tomamos a nosso serviço dez homens, uns para tratar dos animais de carga, outros como caçadores. Todos bem armados, seguimos viagem, providos das necessárias munições e todos os requisitos para colecionar exemplares de história natural, parte dos quais eu trouxera desnecessariamente da Europa. ${ }^{32}$

\footnotetext{
${ }^{31}$ SCHWARCZ, A longa viagem da biblioteca dos reis... pp. 255-260. Ainda sobre a biblioteca da Academia da Marinha, há o artigo de DENIPOTI, Cláudio. Possibilidades combinatórias da condução da leitura em uma biblioteca. José Maria Dantas Pereira e o "Catálogo sistemático da biblioteca da companhia dos guardas-marinhas". Acervo. Rio de Janeiro, v.26, n2 pp.133-145, JUL/DEZ. 2013.
}

${ }^{32}$ WIED-NEUWIED, op.cit. p.40 
Sobre os ares de ciência nessas três regiões analisadas, as observações consideradas são de bibliotecas particulares, bibliotecas conventuais, jardins botânicos e livros. Em Viagem ao Brasil nos anos de 1815 e 1817, de Wied-Neuwied, há uma passagem sobre os espaços de sociabilidade do conhecimento científico em Salvador. Na narrativa, o autor destacou a biblioteca pública e as privadas com acervo dedicado à história natural, às quais, supostamente, ele tivera acesso:

Minha demora na antiga capital do Brasil foi de curta duração; não tive tempo mesmo de visitar os estabelecimentos científicos da cidade, embora fossem ainda em pequeno número. Além da biblioteca pública, para cujo engrandecimento o Conde dos Arcos se empenhou com tanto zelo, o que se tornará de grande valia no difundir das luzes nessa porção do país, encontramse na Baía outras coleções de livros que possuem preciosíssimas obras antigas e modernas. Vários conventos, como, por exemplo, o dos franciscanos, possuem manuscritos antigos curiosíssimos sobre o Brasil. Vivem também nas cidades alguns sábios, entre os quais o sr. Antônio Gomes, correspondente do conde de Hoffmannsegg de Berlim, os Srs. Paiva, Bivar e outros, que se dedicam ao estudo das ciências, e particularmente ao da história natural. Devo à gentileza do primeiro, que possui uma bela biblioteca, alguns escritos interessantes sobre o Brasil, e as obsequiosas informações das várias observações sobre o clima da cidade e dos arredores de São Salvador. ${ }^{33}$

Nos dois tomos da obra, essa é a única referência aos ares científicos na colônia o tal dado levanta a indagação: será que o viajante alemão foi extremamente econômico no tema? Nota-se que no trecho o naturalista esclarece que não teve tempo para os estabelecimentos científicos, mas esses eram poucos. Discorre sobre determinados sujeitos e as coleções de livros públicas e privadas que tinham o papel de difundir as luzes nessa "porção do país".

Ainda que a intenção não seja de recuperar nessas narrativas os espaços baianos existentes, é prudente mencionar que na ocasião da visita de Wied a cidade tinha a Faculdade de Medicina da Bahia (fundada em 1808). Em relação a um Jardim Botânico ou a um Gabinete de História Natural em Salvador durante a estada de Wied, há apenas ordens portuguesas de construção de recinto dessa natureza. Nelson Rodrigues Sanjad analisou o documento expedido no final do século XVIII por D. Rodrigo de Souza Coutinho ao então Governador D. Fernando José de Portugal. Nele, o Ministro orientava a construção de um jardim botânico em Salvador nos moldes do Jardim de São José, na Capitania do Pará que foi criado em 1798 com o apoio de D. Francisco de Souza Coutinho, irmão do Ministro e capitão general do Estado do Grão-Pará e Rio Negro. Na

${ }^{33}$ Ibidem, p. 451 
ordem analisada pelo pesquisador, D. Rodrigo mencionava o envio da cópia de um catálogo de plantas do Horto do Pará. Ele ainda reforçava a importância deste espaço para aprimorar o plantio de árvores que dessem madeira, como também o cultivo de plantas exóticas. ${ }^{34}$ Entretanto, até a passagem de Wied por Salvador, a orientação não havia sido executada.

Por outro lado, há que se lembrar que o alemão ainda viajou por Minas Gerais, Espírito Santo e Rio de Janeiro. Nesta última Capitania, permaneceu um bom período organizando a expedição e conhecendo a cidade e seus arredores. Entretanto, não foram encontradas descrições de bibliotecas privadas e muito menos dos espaços científicos e educacionais existentes na altura como a Real Academia Marinha (1808), o Museu Real (1808), o Real Horto (1810), Escola cirúrgica (1813) e a Real Biblioteca (1814).

Já os viajantes Spix e Martius escreveram sobre os ares científicos do Rio de Janeiro. Mencionaram a Escola Cirúrgica, o Seminário de São Joaquim, a Real Biblioteca, o Real Horto, a Real Academia da Marinha e o Seminário de São José. Sobre os dois últimos, teceram elogios das aulas que lá eram ministradas, bem como as do Liceu do Seminário de São José onde "além do latim, do grego, das línguas francesa e inglesa, retórica, geografia e matemática, também se lecionam filosofia e teologia." ${ }^{35}$ Quando retrataram a Escola Cirúrgica, foram minuciosos, dando-nos informações valiosas sobre suas ideias de ciência, um Passeio Público com plantas notáveis, a coleção de mineralogia e até mesmo de possíveis nomes e temas a serem tratados quando se diz respeito a História Natural:

\begin{abstract}
A História Natural, porém, especialmente, a Botânica, é lecionada por Frei Leandro do Sacramento, um sábio Carmelita de Pernambuco e discípulo do venerado Brotero. Serve-se ele, para as aulas, de uma pequena plantação de vegetais notáveis, feita no Passeio Público, porque o verdadeiro Jardim Botânico se acha situado muito longe da cidade. A coleção de mineralogia, sob superintendência do Sr. Tenente-Coronel von Eschwege, não está em condições favoráveis, porque esse senhor, grande parte do tempo, não reside no Rio de Janeiro. No local dessa coleção encontra-se também um começo do museu zoológico, ainda muito sem importância; pois consta de umas poucas aves empalhadas e de algumas caixas com borboletas diversas. ${ }^{36}$
\end{abstract}

\footnotetext{
${ }^{34}$ SANJAD, Nelson Rodrigues. Nos Jardins de São José: uma história do Jardim Botânico do Grão Pará, 1796-1873. Campinas: Unicamp, 2001 (dissertação de mestrado) p. 84

${ }^{35}$ SPIX, Johann Baptist \& MARTIUS, Carl Friefrich Philipp. Viagem pelo Brasil: 1817-1820. Rio de Janeiro: Imprensa Nacional, 1983.Tomo I p. 54.

${ }^{36}$ Ibidem p. 55-56
} 
Na chegada à cidade, Spix e Martius alugaram uma pequena casa no povoado de Santana, que ficava na encosta de uma colina com vista para o Corcovado. Ali, colocaram seus livros, instrumentos de trabalho e bagagens. ${ }^{37}$ De acordo com Ernst Josef Fittkau, os dois bávaros eram de fácil socialização e foram bem recebidos tanto no grupo de ilustrados que frequentava a casa de Langsdorff, quanto nos círculos oficiais da Corte do Rio de Janeiro. ${ }^{38}$ Isso permitiu o acesso às informações de expedições anteriores, como a de John Mawe, Eschwege e Saint-Hilaire.

Ainda no Rio de Janeiro, iniciaram suas investigações, tiveram contanto com a Real Biblioteca, com 0 Patriota39 e com o trabalho científico de Aires de Casal e Frei Veloso:

A Biblioteca, como se diz, de setenta mil volumes, presente que o rei trouxe
consigo de Portugal para a capital do Brasil, está colocada no edifício dos
Terceiros da Ordem do Carmo. Os assuntos de história e jurisprudência seriam
os mais fartamente representados. Para nós, foi de especial valor o manuscrito
de uma Flora Fluminense, isto é, do Rio de Janeiro, que contém a descrição e
belas figuras de muitas plantas da redondeza, raras ou desconhecidas, e tem
como autor um tal Veloso. [...]
Uma publicação científica que merece, entretanto, menção honrosa, é a
Corografia Brasílica, do Padre Casal, editada em dois volumes, no Rio, obra
que, como primeiro compêndio da geografia geral do Brasil, presta grande
serviço, ainda que quanto à disposição, precisão e exatidão, especialmente sobre
matérias de história natural, muito deixe a desejar. Foi quase que literalmente
traduzida em inglês. ${ }^{40}$

Spix e Martius também percorreram o que hoje são os estados de São Paulo, Minas Gerais, Goiás, Bahia, Pernambuco, Piauí, Maranhão, Pará e Amazonas. Os dois fizeram alguns roteiros separados e o ponto do regresso a Europa foi Belém. Sobre esta parte da viagem, encontrou-se referências aos espaços privados de erudição e de ciência nas Capitanias de Minas Gerais e Bahia.

$\mathrm{Na}$ viagem a Minas Gerais, a primeira menção a esses lugares foi a da biblioteca do Padre Freitas, em Congonhas do Mato Dentro. Segundo os viajantes, a biblioteca contava com algumas obras de Rousseau, Voltaire e a Medicina doméstica de Buchanan. ${ }^{41}$

\footnotetext{
${ }^{37}$ SPIX \& MARTIUS, op. cit. Tomo I p. 47.

${ }^{38}$ FITTKAU, Ernst Josef. Johnn Baptist Ritter von Spix: primeiro zoólogo de Munique e pesquisador no Brasil. Rio de Janeiro: História, Ciências, Saúde - Manguinhos. Vol. III (suplemento), pp. 1112-1114, 2001. p. 1117

${ }^{39}$ Sobre o jornal "O Patriota” há o trabalho KURY, Lorelai. (org.) Iluminismo e império no Brasil: O Patriota (1813-1814). Rio de Janeiro: Editora FIOCRUZ, 2007.

${ }^{40}$ SPIX \& MARTIUS op. cit. Tomo I p. 54 e 55

${ }^{41}$ Idem, p. 18.
} 
Em Sabará, também tiveram contato com a coleção privada de livros do Sr. Teixeira, descrito como "amigo da história natural". Nessa parte do relato, mencionaram os autores presentes cultivava, aclimatava e aprimorava:

Quando ele nos levou à sua biblioteca, vimos com grande prazer, além de alguns livros ingleses e franceses, também as obras de Buffon e uma edição de Lineu, feito pelo nosso compatrício Gmelin. A horta da casa em que ele morava ostentava alamedas de preciosas laranjeiras, cobertas de frutos, várias espécies de pequenas árvores frutíferas europeias e de Mirtáceas brasileiras, de cujo cultivo fazia ele o ensaio, e cujos frutos, já pelos cuidados de poucos anos, haviam melhorado em suco e sabor; viceja aqui especialmente a jabuticabeira." ${ }^{42}$

Somente no III Tomo, os naturalistas narraram outros lugares de produção ou divulgação do conhecimento filosófico natural. Em Salvador, citaram a Escola Cirúrgica e descreveram com um pouco mais de detalhes o Colégio dos Jesuítas, ressaltando a sala da biblioteca em que, na ocasião, constavam 12.000 volumes de clássicos e "obras novas sobre todos os assuntos" Sobre um horto ou jardim, colou-se anteriormente que não havia em Salvador algo semelhante. Por outro lado, há uma passagem sobre o Passeio Público, que ficaria perto do Forte de São Pedro.

As alamedas de laranjeiras, limoeiros jambeiros, mangueiras e árvores da frutapão, as densas e aparadas cercas de pitangueiras, e as renques de variadas plantas ornamentais do sul da Europa, das Índias Orientais e do Brasil, tornam à tarde o mencionado passeio, graças a variação fresca, um lugar aprazível. Do pavilhão da bela baía, ou pousa saudoso no infinito azul do oceano, que o sol poente cobre com cores cintilantes. Entre os jardins que vi no Brasil, este é o que mostra mais os característicos da horticultura europeia. Nele encontrei o arbusto da quásia (Quassia amara L.), cultivado com o nome de quina peruana, que entretanto, não se desenvolve bem. ${ }^{43}$

O Passeio Público de Salvador não era um jardim ou horto botânico nos moldes dos de Madri ou Lisboa, com o plantio controlado, biblioteca e laboratórios químicos. Mesmo assim, pode-se indagar que a descrição acima é significativa por ser a de um estudioso das ciências naturais, com olhar moldado e ferramentas próprias da área? Alguns detalhes, como o de identificação do local de origem das plantas ornamentais seriam mencionados se o narrador fosse um comerciante?

Nobres, burgueses, religiosos, mulheres e homens se dedicaram aos estudos informais sobre as ciências naturais, especialmente nos séculos XVIII e

\footnotetext{
${ }^{42}$ SPIX \& MARTIUS, op.cit. Tomo II, p. 20.

${ }^{43}$ SPIX \& MARTIUS, op.cit. Tomo III, p. 20.
} 
XIX. Entretanto, se um desses entusiastas da natureza realizasse uma viagem, e escrevesse sobre ela, detalhes como nomes científicos e classificações lineanas não eram obrigatórios. Já ao naturalista viajante, essa escolha de escrita não era permitida. É essencial ter em mente que os textos analisados apontam que os nossos sujeitos escreveram para dois tipos de leitores. O primeiro deles é os seus colegas de profissão, em outras palavras, para os seus pares. Seus textos, não obstante, eram lidos em nos salões e gabinetes de leituras das Academias de Ciências e Universidades, dessa forma seguiam regras desse peculiar universo. ${ }^{44}$ Segundo, escreviam para os curiosos e sujeitos não especializados, mas que tinham um conhecimento mínimo dos termos e nomes próprios da história natural. Nessa perspectiva, era importante que o conhecimento do naturalista estivesse nas páginas dos livros de viagem, mesmo que fosse na rápida descrição de um Passeio Público.

Esse esclarecimento reporta a uma das inquirições deste artigo: como historiadoras e historiadores podem estudar as concepções desses objetos e espaços de instrução e de ciência nos livros de viagem? Pode-se entendê-los como elementos narrativos da escrita da cultura científica?

Sobre os jardins botânicos, Wied, Spix e Martius se limitaram a retratar o Real Horto, o Passeio de Salvador hortas e jardins de sujeitos que eles conhecerem durante a viagem. Foi o caso do Sr. Teixeira de Sabará, exposto por Spix e Martius. Apesar de terem percorrido a Capitania do Grão-Pará e partido à Europa da cidade de Belém, não há menção ao Jardim de São José. O que sobressai aos olhos do leitor é o retrato que os viajantes fizeram das bibliotecas. Ambos relataram as bibliotecas de seminários, como a do Colégio dos Jesuítas em Salvador. Entretanto, o destaque foi às coleções particulares de livros.

O que foi escrito por essas pessoas errantes não é o suficiente para se pensar um cenário das coleções privadas de livros e de seus donos. Entretanto, um quadro conciso desses elementos apoia esta investigação sobre os livros de viagem. Luiz Carlos Villalta e Junia Ferreira Furtato apresentam alguns dados quantitativos sobre livros no Brasil no Rio de Janeiro e em Minas Gerais entre 1750 e 1820. Dos 62 inventários cariocas, o primeiro investigador localizou livros em 09. ${ }^{45} \mathrm{Em}$ Mariana, dos 507 inventários examinados, identificou-se

\footnotetext{
${ }^{44} \mathrm{O}$ tema em questão foi aprofundado no artigo: MOSCATO, Daniela Casoni. Pensar, sentir e produzir: as construções do escrito e as estratégias de circulação de memórias naturalistas de luso-brasileiros no século XVIII. Revista de Estudos de Cultura. Sergipe:UFS, Set-Dez, n 9, pp. 147-160, 2017.

${ }^{45}$ VILALTA, Luiz Carlos. Bibliotecas Privadas e Práticas de Leitura no Brasil Colonial. In: MATOSSO, Katia de Queirós; SANTOS, Idelette Muzart Fonseca dos; ROLLAND, Denis [Org.]. Naissance du Brésil Moderne, Actes du Colloque "Aux Temps Modernes: Naissance du Brésil", Sorbornne, Mars 1997. Paris: Presses de l'Université de Paris - Sorbonne,1998. p.05.
} 
livros em 56,11\%. Ainda em Minas Gerais, a historiadora Furtado, que estudou com mais afinco Diamantina, constatou que havia livros nos 14 inventários dos 60 analisados. No Rio de Janeiro, o perfil destes proprietários de livros era, majoritariamente, leigos, detentores de terras e de escravos. Mas também encontrou-se advogados, cirurgiões-médicos e comerciantes. Já na Capitania de Minas Gerais, funcionários da Real extração e padres "rivalizavam quanto a posse de livros." Sobre as bibliotecas e leitores-proprietários, Villalta menciona que o tamanho era, geralmente, determinado pelo grau de escolaridade e intelectualidade. Dessa forma, há nessas décadas uma relação estreita entre os títulos dos livros e a atuação profissional de quem tinha sua posse. ${ }^{46}$

Há ainda um outro elemento significativo nesses estudos sobre bibliotecas e livros no Brasil Colônia. Os investigadores são unânimes em afirmar que livros eram signos de reconhecimento, conhecimento e poder. Sobre o tamanho dessas bibliotecas, as maiores ultrapassavam 400 exemplares. ${ }^{47} \mathrm{O}$ cômodo no qual ficava a estante ou estantes de livros era frequentado pelos convivas locais e viajantes. Lembremos que Wied mencionou a bela biblioteca do Sr. Antonio Gomes, residente em Salvador ${ }^{48}$ e Spix e Martius a do Sr. Teixeira, em Sabará. ${ }^{49}$

Nas duas caracterizações dos naturalistas sobre essas coleções privadas de livros, há informações que dão significados a esses locais. O primeiro fato a ser considerado é o do crescimento nas bibliotecas coloniais de títulos de ciências naturais entre $1750-1820 .{ }^{50}$ Nos relatos sobre as bibliotecas de consulta e particulares havia exemplares de Buffon, Lineu, além dos iluministas como Monstesquieu e Rosseau.

A outra reflexão a se fazer é a d que a referência a tais espaços (jardins e bibliotecas) e objetos (livros) são partes do que os historiadores da História da Ciência denominam como "ciclos de acumulação". Sobre isso, é preciso retomar que os locais de preparo das viagens e de estudos botânicos. Estes espaços (laboratórios químicos, bibliotecas, jardins) e seus sujeitos (mestres em áreas cada vez mais específicas) integravam parte do conjunto que treinou naturalistas viajantes. É importante apreender que era nesses territórios que homens da ciência tiveram acesso ao que Bruno Latour e outros especialistas em história das ciências denominaram de ciclos de acumulação: o

\footnotetext{
${ }^{46}$ Ibidem. pp. 05-09.

${ }^{47}$ Ibidem. p. 09.

${ }^{48}$ WIED-NEUWIED, op.cit. p. 451.

${ }^{49}$ SPIX op. cit. II Tomo, p. 20

${ }^{50}$ VILALTA, op. cit. p. 10.
} 
conhecimento na ideia de ciclos só se estabelece a partir da segunda vez em que ele acontece. Latour é categórico: na "primeira vez que um evento ocorre nada sabemos sobre ele.". ${ }^{51}$ Grosso modo, para que uma experiência de viagem seja reconhecida na cultura científica é necessário que ela se repita e acumule no capital científico - os manuscritos, os livros e as remessas - que estarão disponíveis a outros cientistas.

Nessa premissa, o sucesso desse tipo de viagem era, de certa forma, retornar ao local de partida o conjunto de objetos, amostras dos reinos naturais e dados geográficos e náuticos mais precisos sobre o local investigado. Para compreender melhor essa afirmativa, Latour menciona a experiência de Jean- François de Lapérouse capitão do L'Astrolabe que, em 17 de julho de 1787, atracou na Sacalina. Na altura, pouco se sabia sobre aquela terra e era ela uma marca nebulosa nos mapas do Oceano Pacífico. No L'Astolabe viaja astrônomos, botânicos, mineralogistas e naturalistas. $O$ navio estava equipado dos melhores instrumentos e conhecimentos científicos: relatórios e livros de viagem sobre o Pacífico; relógios; bússolas e carregava todo tipo de mercadoria dada a barganha. Latour destaca o fato de que Lapérouse obteve rapidamente a informação que queria, a de que Sacalina era um ilha, e logo que pode enviou a Versalhes um jovem oficial com os novos dados sobre essa parte do Pacífico. O autor levanta a seguinte questão sobre essa ação de Lapérouse: por quê não ficaram mais na Ilha estudando esse novo lugar? Em sua resposta, Latour lembra que "o interesse que têm pelo lugar é menor que o interesse em levá-lo de volta (...)”:

Se Lapérouse tiver sucesso em sua missão, o próximo navio saberá, antes de avistar a terra, se Sacalina é uma península ou uma ilha, as profundidades do estreito, quais os ventos dominantes, quais os costumes, os recursos e a cultura dos nativos. Em 17 de julho de 1787, Lapérouse é mais fraco que seus informantes; não sabe qual a forma da terra, não sabe aonde ir; está a mercê de seus guias. Dez anos depois, em 5 de novembro de 1797, o navio inglês Neptuna, aportado de novo na mesma baía, estará muito mais forte que os nativos, pois a bordo terão mapas, descrições, livros de bordo, instruções náuticas - graças aos quais, só para começar, eles já saberão que aquela é a "mesma" baía. ${ }^{52}$

Sobre a ideia de acumulação de conhecimento no capital científico, entende-se que as expedições naturalistas no Brasil, e outros lugares, tinham três etapas: o preparo, a viagem e a escrita. Em todas pode-se encontrar os ciclos de acumulação. Na primeira etapa, encontra-se aprendizado e organização

\footnotetext{
${ }^{51}$ LATOUR, op. cit.

${ }^{52}$ LATOUR, op. cit. pp. 352-353.
} 
das expedições ocorridos em instituições - academias, universidades, gabinetes e jardins. Nesses lugares, além da educação formal de história natural, os sujeitos contataram seus pares e se iniciaram na sociabilidade científica. A segunda etapa corresponde à viagem filosófica ou científica. Nesse momento, praticava-se o que havia sido aprendido nos livros e nas aulas, além de reconhecer e conhecer outros naturalistas, seja por meio da leitura, ou mesmo de encontros em suas residências. Por fim, a escrita. 0 tempo da retomada de anotações e da leitura de muitos outros relatos de viagem. Nesse momento, imprimiram-se, em papel, as impressões particulares do trânsito, os significados obtidos pelas leituras de outros textos e a representação de encontros com outros sujeitos viajantes, que eram um objeto de poder, de conhecimento e reconhecimento entre os pares. Cabe lembrar que a publicação de alguns livros de viagens científicas estava muito além da conclusão do trânsito. A experiência retratada trazia estudos meticulosos e identificação de novas espécies, reconhecidos em Academias de Ciências e Universidades ${ }^{53}$. Segundo, porque em suas páginas, encontra-se o acúmulo de experiências de outras viagens, identificado, ora por padrões intertextuais como citações, referências, plágios, alusões, pastiches, etc. ${ }^{54} \mathrm{E}$, terceiro, pelo seu conteúdo em si. Os relatos de viagem tornam-se um objeto científico, "uma vez que resultavam da planificação e aglutinação de diversas inscrições, fossem elas textuais (descrições, coordenadas astronômicas, etc.), fossem imagéticas (ilustrações, mapas, linhas de costas,etc.)" ${ }^{55} \mathrm{O}$ naturalista deveria traçar, sempre que possível, elementos próprios de uma cultura científica consolidada. Nesse conjunto, tem-se além dos nomes científicos de espécies, os momentos de sociabilidade, os espaços e objetos de instrução.

\footnotetext{
${ }^{53} \mathrm{O}$ livro Cosmos de Alexandre Humboldt ilustra significativamente como a publicação da expedição pode apresentar outras formas de se fazer e de escrever sobre a História Natural. VITTE, Antonio Carlos. Natureza em Alexandre von Humboldt: entre a antologia e o empirismo. Mercator, Rio de Janeiro,volume 9, número 20, 2010. set/dez. p. 181. PRATT, Mary Louise. Humboldt e a reinvenção da América. Estudos Históricos, Rio de Janeiro, vol. 4, n. 8, 1991. p.151-165. p. 155. Ainda sobre Humboldt e a circulação de espécies de fauna e flora americanas, há o trabalho de DIENER, Pablo; COSTA, Maria de Fátima. A arte de viajantes: de documentadores a artistas viajantes. Perspectivas de um novo gênero. Revista Porto Arte, Porto Alegre, volumo 15,n.25, Novembro, 2008. pp. 75-89.

${ }^{54} \mathrm{Em}$ outra pesquisa, constatou-se que os nos dois testemunhos de viagem analisados aqui leituras e extratos de livros de outras viagens a essas regiões do Brasil. MOSCATO, Daniela Casoni. O viajante não está só; a cultura científica em memórias sobre o Brasil e as ligações entre os naturalistas luso-brasileiros do século XVIII e os viajantes cientistas do século XIX. Curitiba: Universidade Federal do Paraná, 2017, (tese de Doutorado).

${ }^{55}$ PEREIRA, Magnus Roberto de Mello \& DENIPOTI, Cláudio. Os diários de viagem do doutor Lacerda. A trama de referências no texto de um astrônomo paulista do final do século XVIII. Antíteses, v. 9, n. 18, p. 346-377, 2017. p. 07.
} 
Bibliotecas, livros e jardins: os espaços e os objetos de saberes científicos nos relatos de...

\section{O fim da viagem}

Alguns dos muitos viajantes que percorreram o território português na Europa e na América oitocentistas foram evocados neste artigo. São sujeitos conhecidos e exaustivamente estudados pela historiografia. Entretanto, a relação que essas figuras estabeleceram com os chamados espaços e os objetos de saberes científicos ainda carecem de investigação. No limite destas páginas tentou-se pensar sobre tais elementos. Há de se lembrar que os novos conhecimentos sobre a ciência moderna e sobre a viagem edificaram uma cultura científica especializada, que transitou pelos locais de sociabilidade científica, pelas redes epistolares e pelas leituras de livros de viagem. Esses ambientes e suas práticas são importantes na compreensão das viagens filosóficas, naturalistas ou científicas dos séculos XVIII e XIX.

Os chamados viajantes naturalistas foram para seus contemporâneos a testemunha autorizada nas descrições sobre as ciências naturais. Por isso, escolheu-se para este artigo Maximilian de Wied-Neuwied, Carl Friedrich Philipp von Martius e Johann Baptist Spix. Os três, além de terem percorrido o território brasileiro entre 1815 e 1820, escreveram e publicaram sobre essa experiência naturalista. Nesse sentido, considerou-se a análise dos elementos próprios do universo científico: uso obrigatório de termos, classificações de espécies, menção à exemplares coletados e remessas realizadas. Na documentação, há um conjunto de saberes científicos e que seguiram padrões descritivos como a classificação científica e o recurso às citações bibliográficas. Entretanto, não se pode descartar as especifidades desses objetos e espaços: o retrato que se fez de um Real Horto foi único e distinto, o livro que se carregou durante toda a viagem tem sua significação e a contemplação à biblioteca privada do médico que se estabeleceu nos trópicos foi singular. Nessa toada, percebeu-se que objetos e espaços de saberes eram elementos literários comuns nos escritos e são representados nas passagens pelo Rio de Janeiro, Minas Gerais e Bahia. Nesses lugares, tinha-se a oportunidade de práticas os hábitos da chamada República das Letras: visitar uma biblioteca, ouvir a sessão de leitura de uma memória científica, adquirir publicações, trocar correspondências, assistir a uma aula explanação sobre filosofia natural e integrar os grupos interessados nos materiais de viagens. Esse intercâmbio deveria ser frequentado e alimentado, por isso a adoção de um padrão de valores, linguagens e práticas eram fundamentais.

As muitas menções às bibliotecas particulares brasileiras e seus exemplares reforçam as práticas dos círculos de sociabilidade científica e acompanham os estudos sobre circularidade dos conhecimentos: as informações eram 
difundidas em diversos locais e por diferentes vias. Os livros e os espaços de conversa e debate foram fundamentais nesse processo.

$\mathrm{Na}$ investigação dos dois livros de viagem, percebe-se que, de fato, as reflexões levantadas neste artigo corroboram as pesquisas de outros historiadores que trabalharam com os discursos da literatura de viagem no âmbito da História. Para esses pesquisadores, os viajantes construíram particulares cenários de um mesmo país. Por outro lado, o fato de participarem de uma mesma comunidade científica que se conhecia, se lia e se correspondia, permitia, muitas vezes, a reescrita e apropriação de elementos, descrições e episódios sobre o território brasileiro, seus moradores e sobre quem já havia viajado e escrito sobre esses lugares. Nesta atuação da República das Ciências, também se apresentou o mecanismo do chamado círculo de acumulação que permitia, entre outras dinâmicas, a propagação e repetição de gestos, nomes, hipóteses e narrativas próprias do mundo científico. Como já foi mencionado, nos de ciclos de acumulação o conhecimento só se estabelece a partir da segunda vez em que ele acontece. A escrita sobre locais e objetos de instrução ou de ciência é uma parte desse grande conjunto de repetições e apropriações. Viu-se que o modelo de viajante aqui escolhido tinha o compromisso de trazer para o seu relato de viagem recursos que legitimavam o escrito científico, como os procedimentos de coleta, o preparo e envio das coleções, referências a outros autores e a concepção de espaços de objetos de instrução e científicos.

Neste texto, tentou-se pensar como esses extratos foram descritos por alguns dos viajantes naturalistas que estiveram no Brasil, antes da Independência. Entende-se que tais locais e objetos são partes do ciclo de acumulação que se colocou para muitos sujeitos e, entre eles, o viajante especializado. Nos livros de viagem, era fundamental seguir o padrão de escrita que além das nomenclaturas da fauna e da flora e dos nomes mais importantes da taxionomia de Linneu ou as classificações de Buffon, devia representar a ciência local.

A ideia de acumulação de conhecimento é percebida nos recursos narrativos próprios do campo científico, nos objetos e nos espaços de saberes do Rio de Janeiro, Minas Gerais e Bahia.

Artigo recebido para publicação em 26/04/2018 Artigo aprovado para publicação em 29/10/2018 